\title{
Apoio Multicritério à Decisão para Priorização de Projetos de P\&D: Um estudo de caso em empresa de óleo e gás
}

\section{Title: Multicriteria Decision Aiding for R\&D Project Prioritization: A case study in an oil \& gas company}

\author{
Bruno Candido da Silva1, Éber Assis Schmitzz, Mônica Ferreira da Silvaz, \\ Luís Alberto Duncan Rangel4
}

1,2,3 Programa de Pós-Graduação em Informática - Universidade Federal do Rio de Janeiro (UFRJ) Av. Athos da Silveira Ramos 274 - Rio de Janeiro, RJ - Brasil

\begin{abstract}
4 Departamento de Engenharia de Produção - Universidade Federal Fluminense (UFF) Av. dos Trabalhadores 420, Vila Santa Cecília - Volta Redonda, RJ - Brasil

brunocandido.rj@gmail.com; eber@nce.ufrj.br; monica@nce.ufrj.br; luisduncaneid.uff.br
\end{abstract}

\begin{abstract}
The aim of this paper is to evaluate the viability of applying multicriteria analysis to support decisions in a $R \& D$ portfolio with a high number of projects, multiple sub-portfolios, and a periodic decision-making process. We carried out a case study in the $R \& D$ center of an oil and gas company, in which we used the swing weighting technique for ordering and weighting of the criteria and adopted the Multi-Attribute Utility Theory (MAUT) to rank the projects. We presented the calculated rankings to the portfolio managers in order to validate the method's application and utility. The results of the case study showed that the method is feasible for a portfolio with the characteristics described, with the approval of all the decision makers interviewed.
\end{abstract}

Keywords. Decision support; multicriteria analysis; MAUT; swing weighting; R\&D project portfolio selection.

Resumo. Este artigo se propõe a verificar a viabilidade de aplicação da análise multicritério como ferramenta de suporte à decisão em um portfólio de $P \& D$ com uma grande quantidade de projetos, múltiplas carteiras e um processo periódico de tomada de decisão. Realiza um estudo de caso na área de P\&D de uma empresa de óleo e gás, utilizando a técnica de swing weighting para a ordenação e ponderação dos critérios e a teoria de utilidade multiatributo (MAUT) para ranquear os projetos. Os ranqueamentos obtidos por este processo foram apresentados aos responsáveis pelas carteiras de $P \& D$, a fim de validar a aplicação e a utilidade do método. Os resultados do estudo de caso mostraram que o método é viável para o portfólio com as características descritas, tendo aprovação de todos os decisores entrevistados.

Palavras-Chave. Suporte à decisão; análise multicritério; MAUT; swing weighting; portfólio de projetos de $P \& D$; priorização de projetos.

Cite as: $\quad$ Silva, B. C., Schmitz, E. A., Silva, M. F. \& Rangel, L. A. D. (2020). Apoio Multicritério à Decisão para Priorização de Projetos de P\&D: Um estudo de caso em empresa de óleo e gás (Multicriteria Decision Aiding for R\&D Project Prioritization: A case study in an oil \& gas company). iSys: Revista Brasileira de Sistemas de Informação (Brazilian Journal of Information Systems), 13(1), 5-32. 


\section{Introdução}

As indústrias têm vivido uma enorme agitação em função dos avanços tecnológicos da última década, aliados aos recentes desenvolvimentos nas áreas de tecnologia da informação e engenharia. Inteligência Artificial, Big Data, Computação na Nuvem eram assuntos de um horizonte distante, mas que estão cada vez mais presentes no cotidiano das pessoas. A transformação digital em curso modificará radicalmente os processos, produtos e serviços oferecidos, e as empresas precisarão alterar drasticamente a maneira pela qual realizam os seus negócios, a mentalidade dos seus empregados, bem como se reestruturarem para sobreviver. [Osmundsen, Iden e Bygstad 2018]

Dados são a base da transformação digital [Kloc e Sidi 2017]. Milhões de terabytes de novos dados são criados todos os dias e, com as novas ferramentas tecnológicas, as empresas podem fazer correlações, estabelecer padrões e melhorar suas decisões devido às capacidades analíticas de ferramentas [Vecchio et al. 2017].

Os sistemas de suporte à decisão são ferramentas que processam e organizam a informação de forma a facilitar a tomada de decisão. Modelagem, estruturação e recuperação de dados são os alicerces para que essas ferramentas forneçam resultados eficazes. Iniciativas para o uso de tecnologias inovadoras nos processos de decisão dependerão, igualmente, de um tratamento apropriado dos dados envolvidos.

A decisão de alocar recursos em um subconjunto de propostas é uma importante etapa da gestão do portfólio das empresas [Tervonen, Liesio e Salo 2017]. Quando envolve projetos, a gestão de portfólio compreende processos que visam assegurar o alinhamento dos investimentos realizados com a estratégia da organização. Esses processos são executados de forma cíclica, permitindo a avaliação contínua dos projetos e garantindo o alinhamento permanente do portfólio às revisões da estratégia.

A implementação do apoio à decisão no portfólio de projetos necessita estar embutida nos processos de gestão da organização, a fim de que a implementação seja institucionalizada [Salo, Keisler e Morton 2011], além de evitar a sobrecarga de consultas aos tomadores de decisão e demais participantes do processo. Tais consultas têm $o$ objetivo de obter informações necessárias à decisão, mas que, em função do volume de projetos sob análise - dezenas, centenas ou até milhares - podem inviabilizar a implementação dos métodos de apoio à decisão.

Os projetos de pesquisa, desenvolvimento e inovação (PD\&I ou, simplesmente, P\&D) envolvem gastos elevados, recursos humanos altamente qualificados e uma elevada exposição ao risco. No atual ambiente em constante mudança e incerteza, as organizações dependem de atividades de P\&D para se adaptarem ao crescimento intensivo da tecnologia [Mohagheghi, et al. 2017]. A priorização dos projetos de P\&D vem a contribuir com o melhor aproveitamento dos recursos da organização, potencializando o processo de mudança e justificando o alto investimento envolvido.

Este artigo propõe a aplicação de um método multicritério para auxiliar a priorização dos projetos de $\mathrm{P} \& \mathrm{D}$ de uma empresa de óleo e gás. Foram analisadas as tentativas anteriores de implementação de métodos de suporte à decisão na área de $\mathrm{P} \& \mathrm{D}$ da empresa, a fim de conhecer suas principais virtudes e falhas, e assim propor um modelo mais adequado ao caso específico. Em especial, aprofundamos a análise das pesquisas mais recentes, que propuseram implementar métodos multicritério no processo de priorização, mas que restringiram o escopo da análise a um subconjunto do portfólio, não

iSys: Revista Brasileira de Sistemas de Informação (iSys: Brazilian Journal of Information Systems) 
se atentando às questões envolvidas em uma eventual disseminação do método para todo o portfólio.

O objetivo do artigo é verificar a viabilidade de aplicação da análise multicritério como ferramenta de suporte à decisão no processo de priorização de projetos de $\mathrm{P} \& \mathrm{D}$ da empresa em estudo, tendo como escopo todo o portfólio de P\&D. O desafio consiste em customizar a aplicação do método e torná-lo dinâmico o suficiente para atender às particularidades do processo de priorização em análise - essencialmente, a quantidade elevada de projetos, os múltiplos fóruns de decisão envolvidos e a realização periódica de reuniões para tomada de decisão 1 - oferecendo aos decisores uma ferramenta que os auxilie efetivamente na tomada de decisão.

Espera-se responder a seguinte pergunta: $\mathrm{O}$ apoio multicritério à decisão é uma metodologia aplicável ao processo de priorização dos projetos de $\mathrm{P} \& \mathrm{D}$ da empresa em estudo, caracterizado pela grande quantidade de projetos, múltiplos fóruns de decisão e reuniões periódicas para a tomada de decisão?

Como resultados, espera-se que os ranqueamentos obtidos com base na análise multicritério sejam reconhecidos pelos responsáveis pelas carteiras de P\&D como orientadores das suas decisões, podendo conduzi-los à escolha dos projetos com maior potencial de retorno.

Este artigo está estruturado da seguinte forma: inicialmente é realizada uma revisão bibliográfica sobre os assuntos de interesse e o levantamento das pesquisas mais recentes. Apresentamos também os trabalhos anteriores que utilizaram ou desenvolveram métodos de suporte a decisão na área de P\&D da empresa em estudo. Na sequência, realizamos um diagnóstico da situação atual da empresa e apresentamos a nossa proposta de implementação. Por fim, realizamos uma análise do estudo de caso onde coletamos as percepções dos gestores das carteiras de $\mathrm{P} \& \mathrm{D}$ quanto à utilidade do método e apresentamos nossas conclusões.

Por questões de confidencialidade, as informações dos projetos foram descaracterizadas neste artigo, sem prejudicar os resultados da pesquisa.

\section{Referencial Teórico}

\subsection{Pesquisa e Desenvolvimento}

O Manual de Frascati [Organização de Cooperação e Desenvolvimento Econômico 2013, p.38] define $P \& D$ como "o trabalho criativo empregado de forma sistemática, com o objetivo de aumentar o volume de conhecimentos, abrangendo o conhecimento do homem, da cultura e da sociedade, bem como a utilização desses conhecimentos para novas aplicações".

Segundo Roussel, Saad e Bohlin (1992), há três tipos básicos de P\&D: incremental, radical e fundamental. Essa classificação se baseia nos seus padrões de risco, recompensa, investimento, tempo de obtenção de resultados e possibilidade de proteção. Inicialmente, $\mathrm{P} \& \mathrm{D}$ incremental envolve baixo risco, recompensa modesta e consiste em pequenos avanços tecnológicos, tipicamente fundamentados numa base estabelecida de conhecimento. Já $\mathrm{P} \& \mathrm{D}$ radical consiste na criação de novos conhecimentos técnicos e

1 O processo de priorização envolve em torno de 1200 projetos, 20 comitês de decisão (cada qual responsável por um subconjunto dos 1200 projetos) e 3 rodadas de reunião dos comitês de decisão por ano. 
científicos para um objetivo comercial específico, envolvendo alto risco e alta recompensa. Por fim, há o P\&D fundamental, criando novos conhecimentos para a empresa, e possivelmente para o mundo, com o intuito de ampliar e aprofundar a compreensão sobre uma área técnica ou científica.

Em outra linha de análise, as etapas de desenvolvimento dos projetos de P\&D são demarcadas em função dos níveis de maturidade da tecnologia desenvolvida. O Technology Readiness Level (TRL) é um processo sistemático de medição que suporta a avaliação da maturidade de uma determinada tecnologia e a comparação consistente de maturidade entre diferentes tipos de tecnologia [Mankins 1995]. São definidos nove níveis, sendo o TRL 1 o mais baixo e o TRL 9 o nível mais avançado de maturidade tecnológica. O TRL tem extensa aplicação nas indústrias ligadas a inovação e tecnologia, como, por exemplo, a indústria aeronáutica [Miranda 2016] e a farmacêutica [Yamaguishi 2014].

Tipicamente, os projetos com nível baixo de maturidade estão associados a uma maior exposição ao risco, enquanto os projetos de nível de maturidade mais elevado estão sujeitos a riscos menores. Segundo LeGresley et al. (2000), os níveis de maturidade e os riscos tecnológicos estão inversamente relacionados, ou seja, quanto maior o TRL, menor o risco, e vice-versa. Deve-se, portanto, ter a ideia de que projetos com menor TRL devem ter a promessa de maiores retornos futuros.

\subsection{Projetos e Portfólio de Projetos}

As iniciativas de P\&D são tipicamente conduzidas como projetos. Segundo Gareis (1989), projeto é uma organização estabelecida por um período limitado de tempo a fim de resolver um problema único e relativamente complexo. O PMBOK [Project Management Institute 2018] define o gerenciamento de projetos como "a aplicação de conhecimentos, habilidades, ferramentas e técnicas às atividades do projeto a fim de cumprir os seus requisitos [...] permitindo que as organizações executem projetos de forma eficaz e eficiente".

Em organizações que gerenciam uma quantidade elevada de projetos, o agrupamento e o gerenciamento coordenado dos projetos podem trazer melhores resultados do que se fossem gerenciados isoladamente. Segundo o padrão de gerenciamento de portfólio do PMI [Project Management Institute 2017], o portfólio é uma coleção de projetos que são agrupados de forma a facilitar o gerenciamento do trabalho e com a finalidade de atingir os objetivos estratégicos do negócio. Afirma ainda que o os componentes do portfólio são quantificáveis, ou seja, podem ser medidos, ranqueados e priorizados.

O portfólio reflete os investimentos planejados e realizados pela organização, os quais devem estar alinhados com os objetivos estratégicos do negócio. Se os componentes do portfólio não estão alinhados à estratégia então deve-se questionar a realização do trabalho. Em outras palavras, gerenciar o portfólio significa assegurar que a organização esteja fazendo "o trabalho correto" e não apenas "da forma correta".

O gerenciamento de um portfólio é um processo dinâmico de decisão, em que uma lista de novos produtos e projetos de $\mathrm{P} \& \mathrm{D}$ é constantemente atualizada e revisada. Nesse processo, novos projetos são avaliados, selecionados e priorizados, existindo aqueles que são eliminados ou despriorizados para darem lugar a outros projetos [Cooper, Edgett e Kleinschmidt 2001]. 


\subsection{Análise de Decisão}

Segundo Gomes (2007, p.1), "Decisão é o processo que leva - direta ou indiretamente à escolha de ao menos uma dentre diferentes alternativas, todas estas candidatas a resolver determinado problema".

Para Keeney e Raiffa (1993), a análise de decisão, do ponto de vista técnico, é uma filosofia articulada por um conjunto de axiomas e procedimentos sistemáticos que visam analisar responsavelmente a complexidade inerente a problemas de decisão.

A tomada de decisão visa resolver ou dissolver o conflito de tradeoffs entre os critérios adotados. Quando há apenas um critério, não há tradeoff, ou seja, não existe decisão a tomar. Apenas com critérios múltiplos e não agregados é que podemos ir além da pesquisa e mensuração e considerar um processo de tomada de decisão [Zeleny 2010].

Gomes e Gomes (2014) estabelecem três atores da decisão: o decisor, o facilitador e o analista. O decisor (ou tomador de decisão) influencia no processo de decisão de acordo com o juízo de valor que representa e/ou relações que se estabeleceram. $\mathrm{O}$ facilitador (da decisão) é um líder experiente que deve focalizar a sua atenção na resolução do problema, coordenando os pontos de vista do decisor. O analista (de decisão) é o que faz a análise e auxilia o facilitador e o decisor na estruturação do problema.

Decisões ruins podem prejudicar o negócio. Em muitos casos, elas são consequências de não se ter definido claramente as alternativas, não se ter coletado a informação certa ou não ter sido feita uma análise de custo-benefício com a precisão devida [Hammond, Keeney e Raiffa 1998]. Os autores comentam ainda que muitos erros na tomada de decisões não são devidos ao processo de tomada de decisão, mas estão relacionados com a mente do decisor e a forma como seu cérebro trabalha.

Salo, Keisler e Morton (2011, p.6) defendem que a análise de decisão aplicada a portfólio de projeto é um ramo da análise de decisão tradicional: "Portfolio Decision Analysis (PDA) can be largely viewed as a subfield of decision analysis", argumentando que o PDA possui características próprias que justificam tal subdivisão. $\mathrm{Na}$ seção "Perspectivas para o Futuro", os autores recomendam embutir o PDA nos processos de gestão da organização, aproveitar experiências de tentativas anteriores de implementação, e que consideram aceitável o uso de informações incompletas no processo de estimação

de parâmetros. Tais recomendações constituíram insumos importantes para o trabalho aqui desenvolvido.

\subsection{Apoio Multicritério à Decisão}

O Apoio Multicritério à Decisão consiste em uma metodologia formal e cientificamente fundamentada, que busca uma decisão sólida baseada em uma explicação matemática e em uma avaliação conjunta de múltiplos aspectos do problema. Através de um conjunto de métodos e técnicas, estabelece uma relação de preferências entre diversos fatores intervenientes sob a influência da multiplicidade de critérios, auxiliando pessoas e organizações a tomarem decisões [Magalhães, Rangel e Silva 2017].

Os primeiros métodos de apoio multicritério à decisão sugiram na década de 70 com o intuito de fornecer mecanismos para que decisões complexas, envolvendo vários critérios, fossem tomadas com maior racionalidade. Segundo Gomes, Araya e Carignano (2004, p.02), "os métodos do Apoio Multicritério à Decisão têm um caráter científico e, ao mesmo tempo, subjetivo, trazendo consigo a capacidade de agregar, de maneira ampla, 
todas as características consideradas importantes, inclusive as não quantitativas, com a finalidade de possibilitar a transparência e a sistematização do processo referente aos problemas de tomada de decisão".

Gomes e Gomes (2014, p.88) fazem um esclarecimento importante ao pontuar que "o Apoio Multicritério à Decisão não busca uma solução ótima para determinado problema, como acontece na Pesquisa Operacional tradicional, mas uma solução de compromisso, em que deve prevalecer o consenso entre as partes envolvidas. [...]. Essa abordagem visa, sim, apoiar o processo decisório com a recomendação de ações".

Keeney e Raiffa (1993) introduziram o conceito de se medir a utilidade de cada uma das alternativas disponíveis ao decisor através da Teoria da Utilidade Multiatributo (MAUT - Multi-Attribute Utility Theory). O elemento central dessa teoria é a modelagem das preferências do decisor, considerando-se que o decisor é capaz de identificar várias alternativas discretas a serem avaliadas, bem como estruturar os critérios pelos quais as alternativas serão avaliadas.

Seja $a$ uma alternativa viável e $A$ o conjunto de todas as alternativas viáveis. A cada alternativa $a$ de $A$ são associados $n$ índices de valor $\mathrm{X}_{1}(a), \ldots, \mathrm{X}_{\mathrm{n}}(a)$, onde $\mathrm{X}_{1}, \ldots, \mathrm{X}_{\mathrm{n}}$ correspondente aos $n$ critérios considerados na avaliação. O problema do decisor consiste em escolher a alternativa $a$ em $A$ que melhor o satisfaça com relação ao resultado $\mathrm{X}_{1}(a)$, $\ldots, \mathrm{X}_{\mathrm{n}}(a)$. Dessa forma, é necessário obter uma função que combine $\mathrm{X}_{1}(a), \ldots, \mathrm{X}_{\mathrm{n}}(a) \mathrm{em}$ um índice escalar de "desejabilidade" [Gomes e Gomes, 2014]. Portanto, deve ser definida uma função de valor escalar $v$, conforme a Equação 1:

$$
v\left(x_{1}, x_{2}, \ldots, x_{n}\right) \geq v\left(x_{1}^{\prime}, x_{2}^{\prime}, \ldots, x_{n}^{\prime}\right) \leftrightarrow v\left(x_{1}, x_{2}, \ldots, x_{n}\right) \gtrsim v\left(x_{1}^{\prime}, x_{2}^{\prime}, \ldots, x_{n}^{\prime}\right)
$$

Em que o símbolo $\gtrsim$ significa "preferido ou indiferente a". A função $v$ é denominada função de valor, função de utilidade ou função de preferência. O problema principal consiste em como estruturar e quantificar uma função de valor $v$, de maneira que $v\left(x_{1}, x_{2}, \ldots, x_{\mathrm{n}}\right)=f\left[v_{1}\left(x_{1}\right), v_{2}\left(x_{2}\right), \ldots ., v_{\mathrm{n}}\left(x_{\mathrm{n}}\right)\right]$, onde $v_{i}$ corresponde a uma função de valor sobre o critério $\mathrm{X}_{\mathrm{i}}$.

No caso particular em que se emprega a função de utilidade aditiva, o modelo da MAUT consiste em calcular uma utilidade para cada critério e depois somar essas utilidades, ponderando os critérios de acordo com sua importância relativa aos demais. Para o uso adequado de tal função aditiva, assume-se uma mesma escala, de 0 a 1 , para o domínio comum de cada uma das funções individuais, e que se satisfaça a condição de independência entre os critérios utilizados. (1993):

A Equação 2 descreve a função de utilidade aditiva segundo Keeney e Raiffa

$$
v(x)=\sum_{i=1}^{n} k_{i} v_{i}\left(x_{i}\right)
$$

Em que: $x_{i}$ representa o valor do critério $i$; $v_{i}\left(x_{i}\right)$ é o valor de utilidade do critério $i$; e $k i$ $\left(\operatorname{com} 0 \geq \mathrm{ki}_{\mathrm{i}} \geq 1\right)$ representa um coeficiente de ponderação do critério $i$ tal que $\sum \mathrm{ki}_{\mathrm{i}}=1$.

Publicações recentes sinalizam a utilização do apoio multicritério à decisão em portfólios de projetos de $\mathrm{P} \& \mathrm{D}$. 
Bhattacharyya (2015) considera a seleção de projetos em portfólio de P\&D como um problema de decisão multicritério e propõe uma abordagem usando grey theoryz. Argumenta que na análise multicritério convencional as avaliações e pesos dos critérios são considerados valores numéricos exatos quando, na realidade, os julgamentos realizados pelos tomadores de decisão são incertos e portanto não podem ser expressados com precisão. Realiza um estudo de caso em um portfólio de projetos de $\mathrm{P} \& \mathrm{D}$, em que aplica grey theory e conclui que o método que propõe é consistente e razoável.

Arratia M, et al. (2016) propõem um modelo matemático para otimização de portfólio baseado em programação linear inteira mista. O modelo particiona o projeto em atividades, considerando que cada atividade está associada a um tipo específico de despesa, e indica quais atividades devem ser selecionadas para receber financiamento, estejam elas em um mesmo projeto ou em projetos diferentes. O modelo leva em conta a interdependência entre as atividades e realiza a seleção em função das metas e preferências da organização para os tipos de despesas (compras de equipamentos, despesas de viagem, bolsas de estudo, taxas de publicação). O artigo conclui que é possível, com os recursos computacionais atuais, trabalhar com modelos que permitam uma representação detalhada das características do mundo real - tarefas, sinergias e múltiplas políticas de financiamento - e resolver problemas de otimização de portfólio de forma eficiente.

Mohagheghi, et al. (2017) apresentam um modelo baseado em lógica fuzzy para priorizar projetos de $\mathrm{P} \& \mathrm{D}$, sem no entanto utilizar métodos do apoio multicritério à decisão. Propõem uma abordagem para avaliação de riscos e para a seleção de projetos usando conjuntos fuzzy tipo 2 intervalar (IT2FS). Segundo os autores, essa abordagem se diferencia das demais por possibilitar considerar, simultaneamente, o risco e retorno esperado dos projetos, oferecendo o portfólio não apenas com a melhor taxa de retorno, mas também com o menor risco. Para ilustrar as capacidades do modelo, realizaram um estudo de caso no portfólio de P\&D de uma empresa de óleo e gás.

Çağlar e Gürel (2018) analisam o problema de seleção de projetos em portfólio de P\&D sob a ótica da alocação de recursos orçamentários entre setores de uma organização pública. Apresentam um modelo em duas fases, em que a primeira trata do balanceamento dos recursos entre os setores em função dos resultados esperados pelos projetos de P\&D propostos, e a segunda de fornecer ao tomador de decisão um método para maximizar o seu portfólio de projetos tendo como restrição o recurso setorial aprovado. Aplicam o modelo proposto em um problema-exemplo e comparam os resultados obtidos com as políticas de distribuição de recursos e de seleção de projetos aplicadas na organização analisada.

\subsection{Evolução do suporte à decisão na empresa em estudo}

Foi realizado um levantamento de trabalhos anteriores que utilizaram ou desenvolveram métodos de suporte a decisão para os projetos de P\&D na empresa em estudo, com o objetivo de assimilar as lições aprendidas e incorporar, no método ora proposto, o melhor das experiências pregressas.

\footnotetext{
2 A grey theory, ou teoria de sistemas cinzas, é um método matemático usado para avaliar incertezas em sistemas. Parte do princípio que sistemas reais estão situados em uma faixa cinzenta entre um sistema cujas informações são totalmente conhecidas (sistemas "brancos") e um sistema cujas informações são totalmente desconhecidas (sistemas "caixa-preta").
} 
Gonzaga e Menezes (1997) deram início às discussões sobre a formalização do processo de priorização de projetos de $\mathrm{P} \& \mathrm{D}$, estabelecendo critérios padronizados para a avaliação dos projetos e propondo um método para a tomada de decisão. Segundo as autoras, "A proposta do projeto deve ser apresentada enfocando critérios de atratividade predefinidos: economicidade, aplicabilidade, grau de interesse do cliente, probabilidade de sucesso técnico, abrangência, impacto ambiental, segurança operacional e inovação [...]. Nas reuniões dos comitês, os projetos recebem notas para cada critério de atratividade e são classificados a partir da média geral obtida”.

Rodriguez (2000) propôs uma evolução no trabalho de Gonzaga e Menezes, abordando os seguintes pontos:

- Revisão dos critérios utilizados para priorização, aplicando o método Delphi para obter os critérios mais relevantes junto aos participantes do processo;

- Utilização do método Knowledge-Discovery in Databases (KDD) como forma de recuperação de informações, após observar que os critérios não estavam disponíveis em bases de dados que permitissem o processamento necessário;

- Como estudo futuro, propôs o desenvolvimento de um sistema de informação que pudesse suportar as decisões sobre os projetos de $\mathrm{P} \& \mathrm{D}$, usando como base os métodos de priorização propostos.

Leite (2008) inicia a abordagem da seleção de projetos de P\&D sob a ótica da gestão de portfólio e propõe uma metodologia para a seleção, avaliação e priorização de projetos baseando-se na avaliação de critérios padronizados, numa visão mais abrangente de portfólio. De acordo com o autor, "o sucesso da gestão de um portfólio depende de múltiplos aspectos e não pode ser medido por uma métrica simples[...] em razão disso foi criada uma metodologia baseada em seis importantes parâmetros [...] que ajudou a identificar o que significa um bom portfólio de projetos".

Zink (2009) propôs a utilização da metodologia Analytic Hierarchy Process (AHP) para auxiliar a seleção de projetos de P\&D do segmento de Abastecimento. Segundo a autora, "a metodologia AHP oferece uma sistemática onde se podem colocar elementos de um problema em forma hierárquica e, com base na utilização de julgamentos e preferências, estabelecer prioridades para a tomada de ação". Estruturou o processo da carteira INOVA (Programa Tecnológico de Inovação em Combustíveis) utilizando sete critérios - Impacto competitivo, Impacto social, Impacto ambiental, Inovação, Abrangência, Prazo de implantação e Probabilidade de sucesso - que foram ponderados usando os pesos 1-baixo, 3-médio e 5-alto. Tanto a avaliação como a ponderação dos critérios foram atribuídos de forma "qualitativa, subjetiva e intuitiva" [Zink 2009, p. 32] pelo gestor da carteira INOVA e serviram como base para o ranqueamento dos 44 projetos da carteira.

A principal contribuição de Zink foi ter sido a pioneira na aplicação da análise multicritério nos projetos de $\mathrm{P} \& \mathrm{D}$ da empresa. Considera-se, no entanto, que a atribuição manual de valores para os critérios seja contraproducente, por exigir repetidas consultas ao gestor da carteira a cada rodada de decisão, além de não racional, por ser realizada de forma subjetiva e intuitiva. Ademais, considera-se a escala de pesos utilizada (1-baixo, 3médio e 5-alto) insuficiente para uma ponderação de critérios satisfatória, sendo recomendada a Escala Fundamental de Saaty [Saaty 1980] para o método aplicado (AHP), a qual utiliza números inteiros de 1 a 9 e uma descrição padronizada dos valores. 
Saramago (2010) utilizou a teoria de utilidade multiatributo (MAUT) como método para ordenação dos projetos e a técnica de Swing Weighting para a ponderação dos critérios, restringindo o escopo da sua pesquisa à carteira de Engenharia de Poço e apenas às novas propostas de projetos da carteira (10 propostas). Adotou nove critérios Economicidade, Competitividade, Prazo de Implantação, Exequibilidade, Probabilidade de Sucesso, Teor de Inovação, Abrangência, Impacto no Meio Ambiente e Impacto na Segurança Operacional - realizando, assim como no trabalho de Zink, um processo manual de atribuição de valores.

Considera-se que as técnicas multicritério utilizadas por Saramago foram acertadas, em função da praticidade, versatilidade e adequação das técnicas ao caso estudado, bem como passíveis de serem aplicadas em maior escala. Por essa razão, a presente pesquisa optou por adotar as mesmas técnicas das de Saramago - MAUT para ordenação dos projetos e Swing Weighting para ponderação dos critérios. Entretanto, algumas características do modelo de Saramago - a citar: a não-observância às particularidades de cada área de pesquisa, a limitação do universo de análise a somente às novas propostas de projeto e a coleta manual de dados - necessitaram ser revistas para uma disseminação apropriada do método para todo o portfólio de P\&D.

Os trabalhos de Zink (2009) e Saramago (2010) assemelham-se por:

- Aplicar a análise multicritério em um segmento específico (Abastecimento, caso de Zink, e Engenharia de Poços, no caso de Saramago);

- Aplicar o método somente às novas propostas de projetos, não incluindo os projetos em andamento;

- Requerer a atribuição ou revisão dos valores dos critérios dos projetos a cada nova rodada de decisão.

A Figura 1 ilustra a evolução das práticas de suporte à decisão na área de P\&D da empresa em estudo.

\begin{tabular}{ccccc|}
$\begin{array}{c}\text { Metodologia para } \\
\text { Priorização }\end{array}$ & $\begin{array}{c}\text { Recuperação } \\
\text { de dados }\end{array}$ & $\begin{array}{c}\text { Portfólio de } \\
\text { Projetos }\end{array}$ & $\begin{array}{c}\text { Apoio Multicritério } \\
\text { à Decisão (Abast.) }\end{array}$ & $\begin{array}{c}\text { Apoio Multicritério } \\
\text { à Decisão (Poços) }\end{array}$ \\
\hline 1997 & 2000 & 2008 & 2009 & 2010 \\
Gonzaga e Menezes (1997) & Rodriguez (2000) & Leite (2008) & Zink (2009) & Saramago (2010) \\
\hline
\end{tabular}

Figura 1 - Histórico do suporte à decisão na empresa

Constata-se uma evolução no emprego de métodos para apoiar as decisões sobre os projetos de $\mathrm{P} \& \mathrm{D}$, bem como um esforço permanente da empresa para aperfeiçoar os processos que cercam as atividades de pesquisa e desenvolvimento. Verifica-se também o valor conferido pela empresa, historicamente, ao processo de priorização dos projetos.

\section{Diagnóstico da situação}

\subsection{O Sistema Tecnológico da empresa}

O Sistema Tecnológico é o modelo corporativo para gestão da tecnologia da empresa em estudo. Compreende o modelo de governança e o conjunto de processos organizacionais voltados ao atendimento das demandas tecnológicas atuais e futuras da empresa, 
abrangendo desde o desdobramento do Planejamento Estratégico até a incorporação de tecnologias nos processos produtivos.

Com o intuito de assegurar o alinhamento das iniciativas de P\&D com o Planejamento Estratégico, a empresa realiza, a cada dois anos, um processo de Direcionamento Tecnológico onde são estabelecidas as grandes metas de tecnologia. No primeiro nível, tais metas são denominadas Focos Tecnológicos.

Os Focos Tecnológicos são desdobrados em elementos menores e mais tangíveis, denominados Desafios Tecnológicos. Os projetos de P\&D são desenvolvidos visando atender os Desafios Tecnológicos propostos, garantindo o alinhamento entre as iniciativas de $\mathrm{P} \& \mathrm{D}$ e a estratégia tecnológica da companhia, conforme ilustrado na Figura 23.

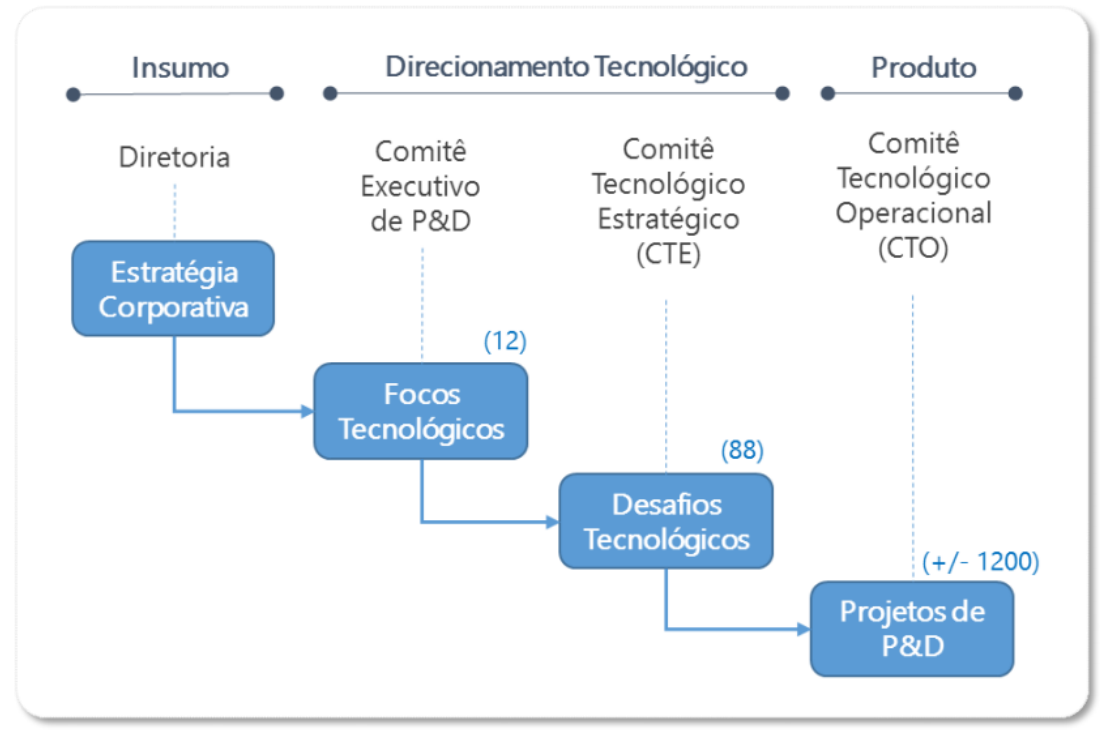

Figura 2. Processo de Direcionamento Tecnológico.

A definição dos Focos, Desafios e Projetos de P\&D é realizada por comitês de decisão organizados conforme o seu nível de atuação na empresa:

- O Comitê Executivo de P\&D define a estratégia tecnológica corporativa, produzindo os Focos Tecnológicos;

- Os Comitês Tecnológicos Estratégicos (CTE) desdobram a estratégia tecnológica nos segmentos de negócio, gerando os Desafios Tecnológicos;

- Os Comitês Tecnológicos Operacionais (CTO) são os responsáveis pela seleção dos projetos de $\mathrm{P} \& \mathrm{D}$ que irão atender aos desafios tecnológicos. Por ser o comitê de decisão dos projetos de $\mathrm{P} \& \mathrm{D}$, o CTO é um dos personagens principais desse estudo.

Uma das atribuições do CTO é analisar as propostas de novos projetos de P\&D. A entrada de um projeto de P\&D no Sistema Tecnológico ocorre por meio de uma Proposta de Projeto de P\&D (PPP), contendo informações básicas relacionadas ao seu escopo, prazo, custo e alinhamento estratégico. Uma vez priorizada pelo CTO, a PPP se torna efetivamente um projeto, passando a fazer parte do portfólio de P\&D. 
A partir desse momento, o projeto passa a ser avaliado continuamente pelo CTO, podendo prosseguir sua execução ou ser encerrado. Essa avaliação é feita periodicamente, a cada quatro meses, quando o CTO se reúne para avaliar a carteira de projetos de P\&D sob sua responsabilidade. A Figura 3 ilustra o esquema de realização desse processo.

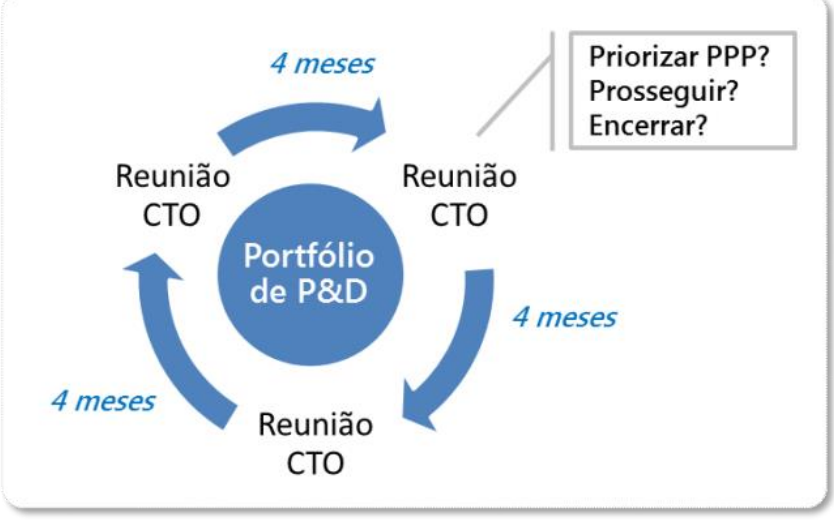

Figura 3 - Avaliação contínua do portfólio de P\&D.

O portfólio de projetos de P\&D da empresa em estudo é organizado em agrupamentos menores - carteiras de projetos - que, por sua vez, são compostos por projetos (Figura 4). Há um total de 20 carteiras de projetos (e 20 CTO's), por onde estão distribuídos os mais de 1200 projetos e propostas de projetos de P\&D.

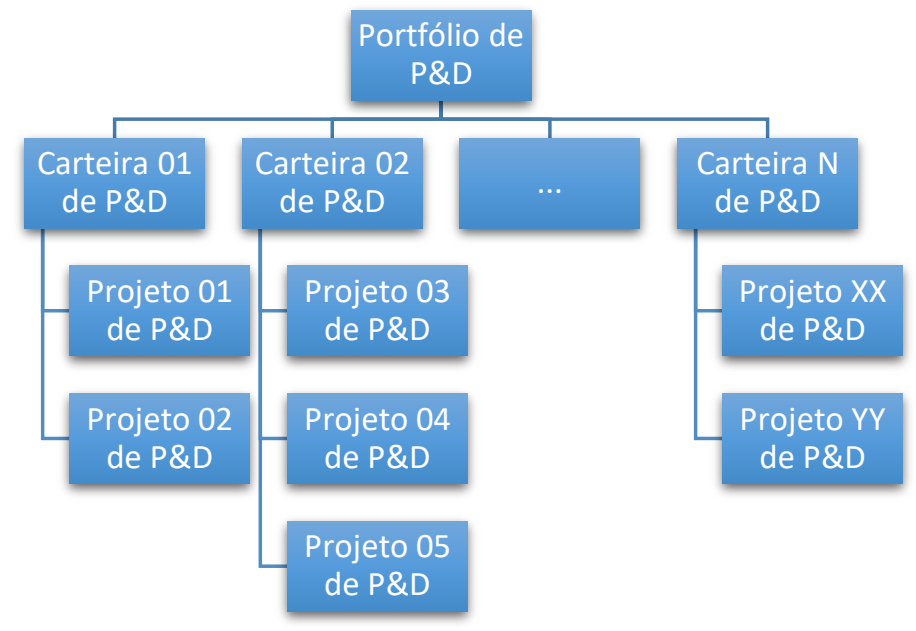

Figura 4 - Estrutura de portfólio, carteiras e projetos de P\&D.

\subsection{Atual processo de priorização de projetos de $P \& D$}

A pesquisa de Zink (2009) e, mais diretamente, a de Saramago (2010), serviram como base para o mais recente processo de priorização de projetos de $\mathrm{P} \& \mathrm{D}$ adotado pela empresa. Entretanto não constava no escopo de atuação dessas pesquisas as questões ligadas à operacionalização do modelo e à disseminação do método para a totalidade do portfólio.

No ano de 2012, por iniciativa da empresa, o trabalho de Saramago foi desdobrado para as demais carteiras de P\&D. O modelo se manteve em uso até 2016, tendo sido descontinuado pelos motivos que seguem: 
- O trabalho foi concebido e implementado originalmente em uma das 20 áreas de pesquisa da empresa, sendo desdobrado posteriormente para as demais. Os critérios propostos inicialmente não foram revisados à luz das características e necessidades de cada área de $\mathrm{P} \& \mathrm{D}$, implicando em falta de interesse das áreas não atendidas e desuso do modelo com o passar do tempo;

- O modelo proposto considerava apenas as novas propostas de projetos (PPP's), fornecendo um ranqueamento que não incluía os projetos em execução. Embora facilitasse a escolha das PPP's a priorizar, o ranqueamento nada dizia sobre os projetos em execução, tampouco permitia a comparação destes com as novas propostas de projeto. Cumpre destacar que os projetos em execução e as PPP's concorrem pelos mesmos recursos de $\mathrm{P} \& \mathrm{D}$, não havendo motivo para a separação das partes no processo de decisão do CTO;

- $\mathrm{O}$ modelo proposto não se atentou à quantidade de consultas necessárias para o fornecimento das informações requeridas para a análise multicritério. Foram estabelecidos nove critérios, cujos valores eram coletados a cada reunião de CTO, em consulta a avaliadores pré-definidos. Considerando o conjunto de 1200 projetos, 9 critérios e uma média de 3 avaliadores por projeto, calcula-se a coleta de 32.400 informações a cada rodada de reuniões de CTO. Considerando a periodicidade de 4 meses para as reuniões de CTO, chega-se a 97.200 coletas de informação por ano, inviabilizando o processo.

A partir de 2017, a priorização dos projetos de $P \& D$ passou a ser realizada sem o suporte da análise multicritério, com cada área de pesquisa decidindo ao seu modo a composição da sua carteira de projetos.

\section{A Proposta}

Segundo Keeney e Raiffa (1993, p.64), “qualquer tentativa de análise formal de um problema de decisão complexo requer uma articulação dos objetivos do tomador de decisão e uma identificação de atributos úteis para indicar a extensão em que esses objetivos são alcançados". Portanto a efetividade do processo de identificação dos atributos (critérios) relevantes para a priorização, depende de uma definição clara e consistente do objetivo.

Sendo assim, foi solicitada à área de gestão tecnológica do Centro de Pesquisas uma definição sobre o objetivo da priorização dos seus projetos de P\&D. Chegou-se a seguinte definição: "Atender aos desafios tecnológicos da organização, maximizando os resultados da carteira e cumprindo as obrigações de investimento em P\&D”.

Com base nos motivos que levaram à interrupção do último modelo de priorização adotado, bem como no levantamento histórico realizado pelo presente artigo, que analisou os trabalhos anteriores de suporte a decisão na empresa em estudo, foi proposta a aplicação de um método multicritério com os seguintes requisitos:

- Consulta a gestores dos quatro grandes segmentos de P\&D da empresa, de forma a captar de forma abrangente os critérios relevantes para a priorização e envolver todas as partes na estruturação do processo decisório; 
- Abranger tanto as propostas de novos projetos, como os projetos de P\&D já em execução, tendo em vista que ambos concorrem pelos mesmos recursos da carteira de P\&D;

- Utilização de critérios cujas informações estejam disponíveis nas bases de dados da empresa, de forma que o processo de decisão e realização dos CTO's não fosse impactado pelas necessidades de coleta de dados do modelo multicritério;

- Permitir que critérios possam ser revisados pelos coordenadores de CTO de forma prática e dinâmica, sem que todo o modelo de priorização necessite ser revisto.

\subsection{Entrevistas com os coordenadores de CTO}

Foram entrevistados gerentes das áreas de pesquisa com a função de coordenar os CTO's e priorizar os projetos de P\&D. Pelo papel que desempenham nas carteiras de $\mathrm{P} \& \mathrm{D}$, estes gerentes são chamados na empresa de "Coordenadores de CTO".

Nesse estudo de caso, foram entrevistados quatro coordenadores de CTO, cada qual representando um dos quatro grandes segmentos de P\&D da empresa, conforme representado na Tabela 1:

Tabela 1 - CTO's participantes do estudo de caso

\begin{tabular}{|l|l|}
\hline CTO & Segmento de P\&D \\
\hline Engenharia Submarina & Desenvolvimento da Produção \\
\hline Elevação e Escoamento & Exploração e Produção \\
\hline $\begin{array}{l}\text { Otimização, Integridade } \\
\text { e Confiabilidade }\end{array}$ & $\begin{array}{l}\text { Integridade, Sustentabilidade e } \\
\text { Otimização }\end{array}$ \\
\hline Energia & Refino e Gás Natural \\
\hline
\end{tabular}

O objetivo das entrevistas foi determinar os critérios a serem usados nas carteiras de P\&D sob responsabilidade de cada coordenador de CTO e, dessa forma, obter as preferências para a seleção de projetos de cada área de pesquisa.

\subsection{Coleta de dados}

A coleta de dados consistiu em dois procedimentos distintos: o primeiro, a entrevista com os coordenadores de CTO, a fim de identificar os critérios e suas relevâncias; o segundo, a recuperação das informações relativas aos projetos nos bancos de dados da empresa.

\subsubsection{Definição, ordenação e ponderação dos critérios}

Foi elaborada uma listagem inicial de critérios, com o objetivo de facilitar a definição dos critérios pelos coordenadores de CTO. Essa lista inicial foi elaborada pela gerência responsável pela gestão tecnológica do Centro de Pesquisas e consiste numa listagem de sete critérios previamente analisados e entendidos como de potencial interesse para a priorização dos projetos de P\&D (Tabela 2). 
Tabela 2 - Critérios para análise do coordenador do CTO

\begin{tabular}{|c|c|c|c|}
\hline Critérios & Descrição & Observação & Objetivo \\
\hline CAPEX & $\begin{array}{l}\text { Orçamento total previsto para a conclusão do } \\
\text { projeto }\end{array}$ & $\begin{array}{l}\text { Para os projetos em execução, trata-se } \\
\text { do orçamento previsto até a conclusão. }\end{array}$ & Minimizar \\
\hline $\begin{array}{l}\text { Obrigação ANP } \\
\text { ou ANEEL }\end{array}$ & $\begin{array}{l}\text { Parcela do orçamento a ceita pelo órgão } \\
\text { regulador (ANP/ANEEL) como obrigação de } \\
\text { investimento }\end{array}$ & & Maximizar \\
\hline $\begin{array}{l}\text { Benefício (ret. } \\
\text { Financeiro) }\end{array}$ & $\begin{array}{l}\text { Retorno financeiro esperado após a } \\
\text { implementação do projeto }\end{array}$ & $\begin{array}{l}\text { Processo de Valoração conduzido pela } \\
\text { Estratégia. }\end{array}$ & Maximizar \\
\hline $\begin{array}{l}\text { Risco Técnico } \\
\text { do Projeto }\end{array}$ & $\begin{array}{l}\text { Risco do projeto não atingir o patamar técnico } \\
\text { esperado. Avaliado em função do seu nível de } \\
\text { maturidade tecnológica (TRL). }\end{array}$ & $\begin{array}{l}\text { Quanto mais alto o nível de } \\
\text { maturidade tecnológica, menor o risco } \\
\text { associado ao projeto. }\end{array}$ & Minimizar \\
\hline Prazo & $\begin{array}{l}\text { Tempo necessário para o desenvolvimento do } \\
\text { projeto }\end{array}$ & $\begin{array}{l}\text { Para os projetos em execução, trata-se } \\
\text { do tempo restante até a conclusão. }\end{array}$ & Minimizar \\
\hline Avaliação & $\begin{array}{l}\text { No caso de PPP, são as revisões por pares, que } \\
\text { podem ser "Favorável", "Neutra" ou } \\
\text { "Contrária". No caso de projeto, o índice de } \\
\text { cumprimento de marcos. }\end{array}$ & & Maximizar \\
\hline $\begin{array}{l}\text { Alinhamento } \\
\text { Estratégico } \\
\text { (gap analysis) }\end{array}$ & $\begin{array}{l}\text { Índice que avalia o gap de alinhamento } \\
\text { estratégico do projeto. }\end{array}$ & $\begin{array}{l}\text { Deseja-se minimizar as lacunas (gaps) } \\
\text { entre os projetos e os Desafios } \\
\text { Tecnológicos estabelecidos. }\end{array}$ & Minimizar \\
\hline
\end{tabular}

Para cada critério, foi estabelecida uma função de utilidade, conforme a Figura 5, onde o eixo horizontal (x) representa o critério avaliado e o eixo vertical (v) a utilidade do critério. Foi utilizada a função matemática $v(x)=x$ para os critérios em que o objetivo do coordenador, à luz da priorização dos projetos de $\mathrm{P} \& \mathrm{D}$, é maximizar o critério, e a função $v(x)=1 / x$ quando o objetivo é minimizar o critério. [Gomes e Gomes, 2014, p.111]
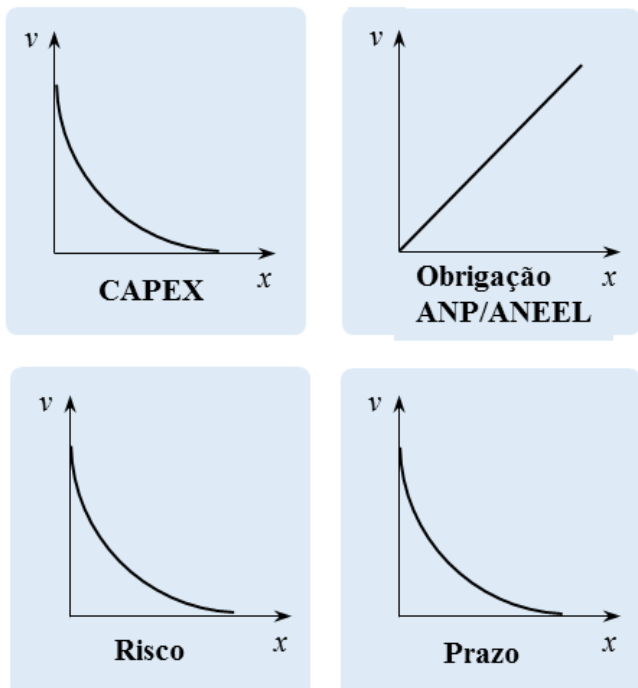
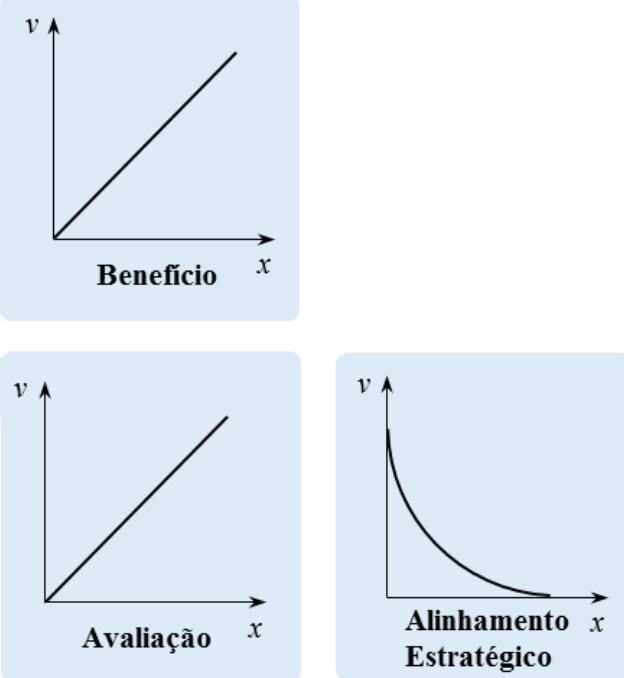

Figura 5 - Funções de utilidade dos critérios selecionados

Foram realizadas entrevistas com os coordenadores de CTO com o objetivo de: definir os critérios relevantes na avaliação do projeto de $\mathrm{P} \& \mathrm{D}$; ordenar os critérios conforme sua relevância; e graduar (ponderar) a importância relativa de cada critério, levando-se em consideração o objetivo da priorização dos projetos de P\&D.

As entrevistas com os coordenadores de CTO foram realizadas entre agosto e setembro de 2018, tendo uma duração média de uma hora, cada. 


\section{Definição}

A primeira etapa da entrevista consistiu em apresentar e explicar ao coordenador do CTO o significado de cada critério. Em seguida, o entrevistado foi inquirido se todos os critérios eram relevantes para a priorização, se os critérios eram independentes entre si e se suas funções de utilidade estavam adequadas ao problema de decisão. Todos os coordenadores de CTO entrevistados consideraram todos os critérios relevantes para a priorização, independentes entre si e com suas funções de utilidade aderentes.

Além de validar os critérios de interesse, o coordenador do CTO foi questionado se haveria critérios que considerasse relevantes para a priorização, mas que não apareciam na listagem inicial. Foram levantados os seguintes critérios: desempenho do projeto; grau de alinhamento do projeto com a estratégia; contribuição ao índice de segurança TAR (Taxa de Acidentados Registráveis); grau de disrupção do projeto de P\&D e taxa de "mortalidade" ou taxa de implantação com sucesso dos projetos de P\&D. Os dois primeiros critérios foram incluídos no cardápio, modificando a proposta original dos critérios "Avaliação" e "Alinhamento Estratégico". Os demais não foram utilizados neste estudo de caso em função da indisponibilidade ou inexistência da informação nos bancos de dados da empresa. Entendemos não haver impedimento para o uso futuro de tais critérios, sendo necessária a inserção dos dados correspondentes nos processos de gestão da empresa.

\section{Ordenação}

Para a ordenação e ponderação dos critérios, foi utilizado o método Swing Weighting, que consiste na comparação individual dos atributos diretamente imaginando um resultado hipotético [Clemen e Reilly 2013]. Segundo os autores, o método "tem uma vantagem incorporada, pois ele é sensível ao intervalo de valores que um atributo assume" [Clemen e Reilly 2013, p.733].

O primeiro passo do método Swing Weighting consiste em definir uma situação hipotética em que uma alternativa esteja com a pior avaliação possível em todos os critérios. O passo seguinte consiste na indicação de um critério a ser escolhido para elevar o desempenho da alternativa hipotética. Feita a indicação, exclui-se esse critério e repete-se o processo até que se esgotem todos os critérios.

Como exemplo, imaginemos uma situação em que se deseja escolher uma casa para morar e que os critérios levados em consideração sejam a quantidade de cômodos, a distância para o trabalho e a segurança. Uma situação hipotética com a pior avaliação possível seria uma casa com um único cômodo, muitíssimo distante do trabalho e com a segurança avaliada em zero, numa escala entre 0 e 10 . O passo seguinte, de acordo com o método, seria o tomador de decisão indicar um desses critérios para melhorar a fím de elevar o seu interesse pela casa. Supondo que o tomador de decisão entendesse como aceitável morar uma casa com um único cômodo, muito distante do trabalho, mas que o nível de segurança fosse o melhor possível, então a segurança seria o critério indicado por ele. Esse critério seria excluído e o processo repetido, ou seja, o tomador de decisão passaria a avaliar a casa à luz dos critérios quantidade de cômodos e distância para o trabalho. E assim por diante.

Neste estudo de caso, foi feita a seguinte pergunta ao coordenador do CTO: "Considerando-se uma situação hipotética em que um projeto esteja com a pior avaliação possível em todos os critérios, qual critério você selecionaria objetivando elevar o 
desempenho desse projeto?". O critério informado foi considerado como o mais relevante entre todos. Passo seguinte, excluiu-se este critério e repetiu-se a pergunta. O critério selecionado nessa segunda rodada foi considerado o segundo mais relevante, repetindo-se esta sequência até que todos os critérios fossem ordenados.

Como resultado desta etapa, foram geradas as listas ordenadas de critérios de cada uma das carteiras de projetos (Tabela 3 ).

Tabela 3 - Listas ordenadas de critérios por carteira de projetos

\begin{tabular}{|l|c|}
\hline \multicolumn{2}{|l|}{ Engenharia Submarina } \\
\hline $\begin{array}{l}\text { Critérios } \\
\text { Benefício (ret. } \\
\text { Financeiro) }\end{array}$ & 1 \\
\hline $\begin{array}{l}\text { Avaliação } \\
\text { Alinhamento }\end{array}$ & 2 \\
\hline $\begin{array}{l}\text { Estratégico } \\
\text { Obrigação ANP } \\
\text { ou ANEEL }\end{array}$ & 3 \\
\hline $\begin{array}{l}\text { Risco Técnico } \\
\text { do Projeto }\end{array}$ & 5 \\
\hline $\begin{array}{l}\text { Prazo } \\
\text { CAPEX }\end{array}$ & 6 \\
\hline
\end{tabular}

\begin{tabular}{|l|c|}
\hline Otimização, Integr. e Conf. \\
\hline $\begin{array}{l}\text { Critérios } \\
\begin{array}{l}\text { Benefício (ret. } \\
\text { Financeiro) }\end{array}\end{array}$ & Ordenação \\
\hline $\begin{array}{l}\text { Alinhamento } \\
\text { Estratégico }\end{array}$ & 2 \\
\hline $\begin{array}{l}\text { Risco Técnico } \\
\text { do Projeto }\end{array}$ & 3 \\
\hline $\begin{array}{l}\text { Obrigação ANP } \\
\text { ou ANEEL }\end{array}$ & 4 \\
\hline CAPEX & 5 \\
\hline Avaliação & 6 \\
\hline Prazo & 7 \\
\hline
\end{tabular}

\begin{tabular}{|l|c|}
\hline \multicolumn{2}{|l|}{ Elevação e Escoamento } \\
\hline $\begin{array}{l}\text { Critérios } \\
\text { Benefício (ret. } \\
\text { Financeiro) }\end{array}$ & 1 \\
\hline $\begin{array}{l}\text { Avaliação } \\
\text { Alinhamento } \\
\text { Estratégico }\end{array}$ & 2 \\
\hline $\begin{array}{l}\text { Obrigação ANP } \\
\text { ou ANEEL }\end{array}$ & 4 \\
\hline Prazo & 5 \\
\hline CAPEX & 6 \\
\hline $\begin{array}{l}\text { Risco Técnico } \\
\text { do Projeto }\end{array}$ & 7 \\
\hline
\end{tabular}

\begin{tabular}{|l|c|}
\hline Energia \\
\hline $\begin{array}{l}\text { Critérios } \\
\begin{array}{l}\text { Benefício (ret. } \\
\text { Financeiro) }\end{array}\end{array}$ & Ordenação \\
\hline $\begin{array}{l}\text { Risco Técnico } \\
\text { do Projeto }\end{array}$ & 2 \\
\hline $\begin{array}{l}\text { Avaliação } \\
\text { Obrigação ANP } \\
\text { ou ANEEL }\end{array}$ & 3 \\
\hline Prazo & 5 \\
\hline CAPEX & 6 \\
\hline $\begin{array}{l}\text { Alinhamento } \\
\text { Estratégico }\end{array}$ & 7 \\
\hline
\end{tabular}

\section{Ponderação}

Com a ordem dos critérios definida, foi atribuído 100 ao critério de maior relevância, conforme preconizado pelo método Swing Weighting. Em seguida, o coordenador do CTO foi questionado sobre a importância relativa de cada um dos critérios quando comparados com o critério mais relevante, expressando o valor em percentual (entre 0 e 100). Como resultado, foram geradas as listas de critérios ponderadas (Tabela 4).

Tabela 4 - Listas ponderadas de critérios por carteira de projetos

\begin{tabular}{|l|c|}
\hline \multicolumn{2}{|l|}{ Engenharia Submarina } \\
\hline Critérios & Ponderação \\
\hline $\begin{array}{l}\text { Benefício (ret. } \\
\text { Financeiro) }\end{array}$ & 100 \\
\hline Avaliação & 80 \\
\hline $\begin{array}{l}\text { Alinhamento } \\
\text { Estratégico }\end{array}$ & 80 \\
\hline $\begin{array}{l}\text { Obrigação ANP } \\
\text { ou ANEEL }\end{array}$ & 70 \\
\hline $\begin{array}{l}\text { Risco Técnico } \\
\text { do Projeto }\end{array}$ & 60 \\
\hline Prazo & 60 \\
\hline CAPEX & 50 \\
\hline
\end{tabular}

\begin{tabular}{|l|c|}
\hline \multicolumn{2}{|l|}{ Otimização, Integr. e Conf. } \\
\hline Critérios & Ponderação \\
\hline $\begin{array}{l}\text { Benefício (ret. } \\
\text { Financeiro) }\end{array}$ & 100 \\
\hline $\begin{array}{l}\text { Alinhamento } \\
\text { Estratégico }\end{array}$ & 90 \\
\hline $\begin{array}{l}\text { Risco Técnico } \\
\text { do Projeto }\end{array}$ & 85 \\
\hline $\begin{array}{l}\text { Obrigação ANP } \\
\text { ou ANEEL }\end{array}$ & 80 \\
\hline CAPEX & 60 \\
\hline Avaliação & 50 \\
\hline Prazo & 40 \\
\hline
\end{tabular}

\begin{tabular}{|l|c|}
\hline \multicolumn{2}{|l|}{ Elevação e Escoamento } \\
\hline Critérios & Ponderação \\
\hline $\begin{array}{l}\text { Benefício (ret. } \\
\text { Financeiro) }\end{array}$ & 100 \\
\hline Avaliação & 75 \\
\hline $\begin{array}{l}\text { Alinhamento } \\
\text { Estratégico }\end{array}$ & 75 \\
\hline $\begin{array}{l}\text { Obrigação ANP } \\
\text { ou ANEEL }\end{array}$ & 50 \\
\hline Prazo & 40 \\
\hline CAPEX & 30 \\
\hline $\begin{array}{l}\text { Risco Técnico } \\
\text { do Projeto }\end{array}$ & 30 \\
\hline
\end{tabular}

\begin{tabular}{|l|c|}
\hline \multicolumn{2}{|l|}{ Energia } \\
\hline Critérios & Ponderação \\
\hline $\begin{array}{l}\text { Benefício (ret. } \\
\text { Financeiro) }\end{array}$ & 100 \\
\hline $\begin{array}{l}\text { Risco Técnico } \\
\text { do Projeto }\end{array}$ & 50 \\
\hline Avaliação & 50 \\
\hline $\begin{array}{l}\text { Obrigação ANP } \\
\text { ou ANEEL }\end{array}$ & 50 \\
\hline Prazo & 25 \\
\hline CAPEX & 25 \\
\hline Alinhamento & 25 \\
\hline Estratégico & \\
\hline
\end{tabular}

Foi permitido ao entrevistado informar o mesmo grau de importância para dois ou mais critérios, como podemos observar na carteira de Engenharia Submarina, por exemplo, onde os critérios Avaliação e Alinhamento Estratégico foram considerados igualmente relevantes, tendo ambos $80 \%$ da importância do critério Benefício. 
As listas ponderadas são o insumo necessário para os processamentos que se seguiram (normalização, cálculo da soma ponderada e ranqueamento dos projetos).

\subsubsection{Recuperação das informações de projeto nas bases de dados}

As informações dos projetos de P\&D necessárias para o estudo de caso localizam-se em quatro diferentes bases de dados da empresa. Numa primeira base de dados (Workflow de Projetos de P\&D), foram obtidas as informações sobre Capex, Obrigação ANP/ANEEL, Prazo, Alinhamento Estratégico e parte das informações sobre Avaliação (aqueles referentes às propostas de novos projetos). Na segunda base de dados (base de marcos do projeto), foram obtidas as informações sobre a Avaliação dos projetos em execução. Na terceira base de dados (base de TRL), foram obtidas as informações sobre os riscos do projeto, tendo-se em conta que o risco avaliado é inversamente proporcional ao nível de maturidade (TRL) da tecnologia desenvolvida [LeGresley et al. 2000]. Por fim, as informações sobre Benefício foram obtidas numa quarta base de dados (base de valoração de projetos).

Em um processo de estimação de parâmetros para a análise de decisão em portfólio de projetos, a coleta de informação em diferentes bases de dados não representa uma novidade. Segundo Salo, Keiler e Morton, "Portfolio decisions often rely on data that may reside in other IT systems. This would suggest that a greater degree of integration with other IT systems can be helpful in designing decision processes that are linked to sources of information" [Salo, Keisler e Morton 2011, p.21].

As informações coletadas foram concentradas em uma única planilha de dados, por meio da qual foram realizados os cálculos da análise multicritério. O procedimento de carga de dados das bases de dados para a planilha tem duração aproximada de uma hora, carregando as informações sem atraso (D+0). Uma vez carregados os dados, os cálculos ocorrem de forma imediata, sem tempo de processamento perceptível.

Em uma futura implementação do método proposto na empresa, recomenda-se a integração das bases de dados citadas ou a criação de rotinas automatizadas que consolidem as informações em uma única base de dados ou sistema de informação.

\subsection{Apuração dos resultados}

Obtidas as ponderações dos critérios para cada carteira de $\mathrm{P} \& \mathrm{D}$ e os valores dos atributos dos projetos, passamos à etapa de realização dos cálculos e obtenção dos resultados.

\subsubsection{Exemplo}

Visando facilitar o entendimento, foi elaborado um exemplo do emprego do método. A Tabela 5 apresenta três projetos, identificados na coluna "Projeto" e que foram extraídos aleatoriamente da base de projetos utilizada neste estudo de caso. As demais colunas contêm os valores dos atributos (critérios) desses projetos. 
Tabela 5 - Valores brutos dos projetos

\begin{tabular}{|c|c|c|c|c|c|c|c|}
\hline Projeto & Capex & Obrig. & Benef. & Risco & Prazo & Avaliação & Alinh.Est. \\
\hline A & 23,877 & 22,098 & 99,189 & 0,300 & 27 & 2 & 63 \\
\hline B & 97,651 & 64,845 & 96,045 & 0,600 & 39 & 3 & 17 \\
\hline C & 58,891 & 8,043 & 43,503 & 0,400 & 27 & 9 & 216 \\
\hline
\end{tabular}

Os critérios Capex, Obrigação ANP e Benefício estão expressos em milhares de reais. $\mathrm{O}$ critério Risco é um valor entre 0 e 1 , sendo 0 o risco mais baixo e 1 o risco mais alto. $\mathrm{O}$ prazo é medido em meses, enquanto a avaliação e o alinhamento estratégico estão medidos em valores adimensionais.

No passo seguinte, os valores da Tabela 5 são traduzidos com base nas funções de utilidade de cada critério. Para os critérios cujo objetivo seja maximizar (ver coluna "Objetivo" da Tabela 2), aplica-se a função $v(x)=x$. Para os critérios cujo objetivo seja minimizar, aplica-se a função $v(x)=1 / x$. A Tabela 6 apresenta os valores calculados de acordo com as respectivas funções de utilidade.

Tabela 6 - Valores conforme as funções de utilidade

\begin{tabular}{|c|c|c|c|c|c|c|c|}
\hline Projeto & Capex & Obrig. & Benef. & Risco & Prazo & Avaliação & Alinh.Est. \\
\hline A & 0,042 & 22,098 & 99,189 & 3,333 & 0,037 & 2 & 0,016 \\
\hline B & 0,010 & 64,845 & 96,045 & 1,667 & 0,026 & 3 & 0,059 \\
\hline C & 0,017 & 8,043 & 43,503 & 2,500 & 0,037 & 9 & 0,005 \\
\hline
\end{tabular}

Faz-se a normalização dos valores da Tabela 6 pela raiz da soma dos quadrados [Gomes e Gomes, 2014, p.111]. Usando como exemplo o critério "Avaliação" do projeto A, temos: $2 /$ raiz $(22+32+92)=2 /$ raiz $(94)=2 / 9,6954=0,2063$. Conforme Tabela 7 .

Tabela 7 - Valores normalizados

\begin{tabular}{|c|c|c|c|c|c|c|c|}
\hline Projeto & Capex & Obrig. & Benef. & Risco & Prazo & Avaliação & Alinh.Est. \\
\hline A & 0,9038 & 0,3204 & 0,6852 & 0,7428 & 0,6351 & 0,2063 & 0,2598 \\
\hline B & 0,2210 & 0,9401 & 0,6635 & 0,3714 & 0,4397 & 0,3094 & 0,9627 \\
\hline C & 0,3665 & 0,1166 & 0,3005 & 0,5571 & 0,6351 & 0,9283 & 0,0758 \\
\hline
\end{tabular}

O passo seguinte consiste no cálculo dos valores em função dos pesos dos critérios. A Tabela 8 representa a ponderação normalizada dos critérios da carteira de Engenharia Submarina, a qual utilizaremos neste exemplo. Para calcular a Tabela 8, deve-se dividir cada um dos valores da carteira de Engenharia Submarina, apresentados na Tabela 4, pelo somatório destes valores. Por exemplo, para o Capex, o cálculo é: $50 /(100+80+80+70+60+60+50)=0,10$.

Tabela 8 - Ponderação normalizada dos critérios

\begin{tabular}{|c|c|c|c|c|c|c|}
\hline Capex & Obrig. & Benef. & Risco & Prazo & Avaliação & Alinh.Est. \\
\hline 0,10 & 0,14 & 0,20 & 0,12 & 0,12 & 0,16 & 0,16 \\
\hline
\end{tabular}

Multiplicando-se os valores das Tabelas 7 e 8, obtemos os valores ponderados dos atributos dos projetos (Tabela 9)4. Por exemplo, o Capex do projeto A na Tabela 7

4 Para facilitar a leitura, os valores da Tabela 9 foram multiplicados por 100, sem que isso implique em alteração nos resultados. 
$(0,9038)$ é multiplicado pelo peso deste mesmo critério na Tabela $8(0,10)$, resultando em 0,09038 e, conforme explicado na nota de rodapé 4 , multiplicado novamente por 100 , resultando em 9,0380 .

Tabela 9 - Valores ponderados

\begin{tabular}{|c|c|c|c|c|c|c|c|}
\hline Projeto & Capex & Obrig. & Benef. & Risco & Prazo & Avaliação & Alinh.Est. \\
\hline A & 9,0380 & 4,4851 & 13,7039 & 8,9134 & 7,6211 & 3,3005 & 4,1564 \\
\hline B & 2,2100 & 13,1613 & 13,2695 & 4,4567 & 5,2761 & 4,9508 & 15,4031 \\
\hline C & 3,6645 & 1,6325 & 6,0103 & 6,6850 & 7,6211 & 14,8525 & 1,2123 \\
\hline
\end{tabular}

Por fim, os valores ponderados dos critérios de cada projeto são somados, conforme a função de utilidade aditiva exibida na Equação 2, chegando ao resultado final do método, que é o ranqueamento dos projetos, apresentado na Tabela 10.

\section{Tabela 10 - Ranqueamento dos projetos}

\begin{tabular}{|c|c|c|}
\hline Projeto & $\begin{array}{c}\text { Soma } \\
\text { Ponderada }\end{array}$ & $\begin{array}{c}\text { Ranquea- } \\
\text { mento }\end{array}$ \\
\hline A & 51,2184 & 2 \\
\hline B & 58,7275 & 1 \\
\hline C & 41,6782 & 3 \\
\hline
\end{tabular}

Temos, portanto, que o projeto B apresenta o maior valor global, num processo de maximização, seguido dos projetos $\mathrm{A}$ e $\mathrm{C}$, conforme seus valores globais.

\subsubsection{Ranqueamento dos projetos de $P \& D$}

Os ranqueamentos dos projetos das carteiras de P\&D que participaram deste estudo, bem como as fontes de dados que deram origem aos mesmos, estão disponíveis em [Autor 2018].

\section{Análise do caso}

Os ranqueamentos obtidos foram levados à apreciação dos coordenadores de CTO, a fim de obter suas percepções quanto à utilidade do método. Adicionalmente, a consulta aos coordenadores serviu para detectar pontos de melhoria na modelagem do processo decisório, nas formas de emprego do método e nos processos de coleta das informações. As reuniões de ocorreram entre os dias 19 e 31 de outubro de 2018.

\subsection{Avaliação do método pelos coordenadores de CTO}

\section{CTO de Engenharia Submarina (131 projetos)}

Para o coordenador do CTO de Engenharia Submarina, os projetos 12869 e 13339 deveriam estar em posições menos privilegiadas do que a $5^{\mathrm{a}}$ e $7^{\mathrm{a}}$ colocações sugeridas pelo método. Segundo o coordenador, esses projetos não têm relevância que justifique tal posicionamento.

Analisando as bases de informação, detectamos que "Prazo" e "Risco" foram os critérios determinantes para o posicionamento do projeto 12869. Aprofundando a análise, constatou-se um erro na coleta do critério "Risco" na base de dados. Realizada a correção, o projeto foi reposicionado da colocação 5 para a 31 , o que estaria mais próximo da 
verdadeira relevância do projeto, segundo o coordenador do CTO. Com relação ao critério "Prazo", a informação estava correta, não havendo necessidade de alteração.

Relativamente ao projeto 13339, notou-se que "Obrigação ANP/ANEEL" e "Avaliação" foram os critérios determinantes para a $7^{\mathrm{a}}$ colocação obtida. Foi apresentada tal informação ao coordenador do CTO, que acabou por concordar com o posicionamento do projeto, muito embora o critério mais relevante - Benefício - estivesse zerado para esse projeto. Observando este exemplo, percebe-se como o método pode auxiliar e aprimorar a tomada de decisão, por proporcionar ao decisor uma forma de se avaliar os múltiplos aspectos do problema.

Dando sequência à análise, o coordenador do CTO apontou outros dois projetos (o 13354 e o 12910) em situação inversa aos citados acima, ou seja, deveriam estar em posições mais privilegiadas do que a $119^{\mathrm{a}}$ e $120^{\mathrm{a}}$ colocações sugeridas pelo método. Segundo o coordenador, trata-se de projetos muito relevantes para a carteira de P\&D sob análise.

Constatou-se que ambos os projetos 13354 e 12910 têm valores insignificantes para os critérios mais relevantes desta carteira, que são "Benefício", "Avaliação" e "Alinhamento Estratégico". Para os dois primeiros critérios, o valor é zero, significando, para o caso específico, ausência de informação. Neste caso, a ação corretiva consiste no preenchimento da informação ausente pelas equipes responsáveis pelo projeto, estando o coordenador de acordo com tal diagnóstico. Uma vez preenchidas as informações, os projetos inevitavelmente subirão de posição no ranqueamento. Com relação ao critério "Alinhamento Estratégico", o valor está correto, não havendo necessidade de ajuste.

Como pontos de melhoria, o coordenador sugeriu a avaliação do benefício de determinados projetos em termos não-financeiros, citando benefícios de segurança (como a redução do índice de Taxa de Acidentados Registráveis - TAR), e um aprimoramento da avaliação de riscos dos projetos (citando o modelo de Análise Preliminar de Risco APR - adotado em outras áreas da empresa).

Por fim, o coordenador do CTO expressou que, com os devidos ajustes nas bases de informação, tem interesse em utilizar a ferramenta proposta na seleção dos projetos de P\&D da carteira de Engenharia Submarina.

\section{CTO de Otimização, Integridade e Confiabilidade (62 projetos)}

O coordenador do CTO de Otimização, Integridade e Confiabilidade apontou a PPP-0544 e o projeto 13189 , respectivamente nas posições 41 e 43 , como iniciativas importantes dentro da carteira, devendo estar em posições mais elevadas no ranqueamento. Segundo o coordenador, trata-se de iniciativas de transformação digital, assunto de muito interesse no centro de pesquisas. No entanto, as bases de dados da empresa não possuem a indicação dos projetos classificados como transformação digital, impossibilitando o seu uso como critério para priorização. O coordenador compreendeu e foi informado que, uma vez existindo o dado na base, o critério poderia ser inserido no modelo.

Dando sequência, o coordenador informou que o projeto 13168, ranqueado na posição 30, seria mais relevante que os projetos 13160 e 13230, posicionados em 11 e 15, respectivamente. A explicação é que o projeto 13168 não teve o critério Benefício avaliado pelo coordenador, enquanto os demais (13160 e 13230), sim, implicando na diferença de posicionamento entre os projetos. 
Como pontos de melhoria, o coordenador informou que gostaria de uma visualização do ranqueamento que pudesse separar as dimensões de PPP e projeto. Foi informado que tal visualização é factível, não sendo necessárias alterações no modelo proposto.

Por fim, o coordenador manifestou interesse em utilizar o modelo no seu processo de priorização de projetos, tendo inclusive solicitado que se apresentasse o trabalho para os técnicos da sua equipe.

\section{CTO de Elevação e Escoamento (65 projetos)}

Segundo o coordenador do CTO de Elevação e Escoamento, os projetos 11209 e 11210 deveriam estar posicionados em colocações menos favoráveis que a $6^{\mathrm{a}}$ e $7^{\mathrm{a}}$ sugeridas pelo método, considerando a relativa pouca relevância de tais projetos para a carteira de $\mathrm{P} \& \mathrm{D}$ em análise.

Constatou-se que "Alinhamento Estratégico" foi o critério determinante para a posição do projeto 11209 , enquanto "Prazo" foi o determinante para o projeto 11210 . No caso do projeto 11209 , o coordenador compreendeu a razão do bom ranqueamento e comentou que iria propor novos projetos para atender ao desafio tecnológico associado. No caso do projeto 11210, o coordenador foi informado que faltava apenas 2 meses para a sua conclusão e que isso justificaria o projeto estar bem posicionado no ranking, dado que seria contraproducente interromper um projeto tão próximo da sua conclusão. Em ambos os casos, o coordenador concordou com as argumentações.

Além desses casos, o coordenador apontou a PPP-0591, ranqueada na posição 27, como sendo de alta relevância e com um grande retorno financeiro esperado. Foi esclarecido que, de acordo com os processos de gestão de projetos da empresa, o critério que quantifica o retorno financeiro é preenchido em uma etapa posterior à proposição da PPP e, por esse motivo, o critério Benefício não estava ainda avaliado. Dessa forma, a percepção de valor que o coordenador tem sobre a PPP ainda não foi quantificada e, assim que a for, o posicionamento da PPP no ranking irá inevitavelmente melhorar.

$\mathrm{Na}$ parte de baixo do ranqueamento, o coordenador apontou os projetos $11832 \mathrm{e}$ 13611, posicionados nas duas últimas posições, como sendo de grande importância. Igualmente à PPP-0591 citada, tais projetos estão sem o valor de Benefício avaliado. Porém, diferentemente da PPP, tais projetos poderiam dispor da valoração do Benefício pelo coordenador, que comunicou que iria realizá-la.

Como pontos de melhoria, o coordenador sugeriu que as propostas de projeto (PPP's) pudessem ter o Benefício avaliado de forma qualitativa, estimado pela a ordem de grandeza do retorno financeiro esperado para o projeto. Por exemplo, por faixas: Faixa 1: de R \$ 0 a 1 milhões; Faixa 2: de R \$ 1 a 3 milhões; Faixa 3: de 3 a 5 milhões, etc. Dessa forma, haveria um valor minimamente quantificado para as PPP's, que poderia ser usado pelos métodos multicritério.

Também como ponto de melhoria, o coordenador sugeriu que a avaliação do Alinhamento Estratégico pudesse ser feita de acordo com a importância o desafio tecnológico para a companhia. No entanto, foi esclarecido que a empresa não adota graus de importância para os seus desafios tecnológicos, sendo esse o motivo de o alinhamento estratégico estar sendo avaliado em função da lacuna tecnológica medida (gap analysis). 
O coordenador declarou que pretende utilizar o método multicritério proposto como ferramenta de suporte à decisão nas reuniões do CTO de Elevação e Escoamento.

\section{CTO de Energia (55 projetos)}

O coordenador do CTO de Energia informou que não considerava o projeto 13290 , ranqueado na $1^{\text {a }}$ posição, como sendo o mais importante da carteira. Constatou-se que esse projeto foi um dos poucos da carteira de Energia que teve o critério Benefício informado, implicando em uma pontuação elevada para o mesmo e para os demais projetos que tiveram o benefício valorado. Salienta-se que o coordenador do CTO de Energia optou por acentuar a importância relativa do critério Benefício, colocando este critério de duas a quatro vezes mais relevante que os demais.

$\mathrm{Na}$ parte de baixo do ranqueamento, os projetos 12802 e 13517, posicionados respectivamente em $47^{\circ}$ e $55^{\circ}$, foram apontados pelo coordenador como projetos importantes para a carteira de Energia. Analisando os projetos, não se detectou um único motivo para a baixa pontuação dos mesmos e, sim, todos os critérios com baixa avaliação. Foi observado que, assim como em casos anteriores, uma vez valorado o Benefício pelo coordenador, o posicionamento dos projetos melhorará.

O coordenador pretende utilizar o modelo de priorização no CTO e apontou benefícios adicionais trazidos pelo uso do método, como a retroalimentação das informações de projetos em função das avaliações dos critérios e transparência no processo de priorização, tanto para as equipes de projetos, como para os clientes.

\subsection{Quadro resumo das percepções dos coordenadores de CTO}

Todos os coordenadores de CTO consultados manifestaram interesse em utilizar o método multicritério proposto para auxiliá-los na seleção dos projetos de $\mathrm{P} \& \mathrm{D}$ de suas carteiras. Esse é um importante feedback para justificar o investimento de implementação do apoio multicritério à decisão no processo de priorização de projetos de $\mathrm{P} \& \mathrm{D}$ da empresa.

Ademais, foi realizada uma categorização dos retornos fornecidos pelos coordenadores de CTO, bem como a contabilização das ocorrências, conforme Tabela 11.

Tabela 11 - Resumo dos retornos informados pelos coordenadores de СТО

\begin{tabular}{|l|c|c|c|c|c|c|}
\hline Categorias / CTO & $\begin{array}{l}\text { Engenharia } \\
\text { Submarina }\end{array}$ & $\begin{array}{l}\text { Otimização, } \\
\text { Integr. e Conf. }\end{array}$ & $\begin{array}{l}\text { Elevação e } \\
\text { Escoamento }\end{array}$ & Energia & Total & $\%$ \\
\hline $\begin{array}{l}\text { Informação ausente } \\
\text { ou de baixa } \\
\text { qualidade }\end{array}$ & 3 & 1 & 2 & 2 & 8 & $40 \%$ \\
\hline $\begin{array}{l}\text { Esclarecimento ao } \\
\text { coordenador CTO }\end{array}$ & 2 & 0 & 3 & 1 & 6 & $30 \%$ \\
\hline $\begin{array}{l}\text { Erro na coleta de } \\
\text { dados }\end{array}$ & 1 & 0 & 0 & 0 & 1 & $5 \%$ \\
\hline $\begin{array}{l}\text { Interesse por novos } \\
\text { critérios }\end{array}$ & 2 & 1 & 2 & 0 & 5 & $25 \%$ \\
\hline
\end{tabular}

O item "Informação ausente ou de baixa qualidade" refere-se às situações em que, ao longo das entrevistas com os coordenadores, foi constatado que a ausência ou a baixa qualidade da informação impactou a ordenação dos projetos.

O item "Esclarecimento ao coordenador do CTO" refere-se às situações em que o coordenador identificou algum projeto em posição fora do esperado, mas que, ao ser 
informado do motivo, o coordenador compreendeu e concordou com a ordenação sugerida pelo método.

O item "Erro na coleta de dados" refere-se às situações em que foi identificada alguma falha na coleta de dados que acabou por impactar a ordenação dos projetos. Após a identificação, a falha foi corrigida.

O item "Interesse por novos critérios" refere-se às situações em que o coordenador do CTO manifestou interesse pela inclusão de novos critérios no modelo de priorização.

\section{Conclusão}

Esta pesquisa demonstrou que o apoio multicritério à decisão, utilizando-se dos métodos MAUT para ordenar os projetos e Swing Weighting para ponderar os critérios, é aplicável ao problema de priorização de projetos da totalidade do portfólio de $\mathrm{P} \& \mathrm{D}$ da empresa analisada, tendo obtido a aprovação de todos os coordenadores de CTO que participaram do estudo de caso.

Adicionalmente, o estudo permitiu identificar pontos cruciais para que haja uma implementação futura bem-sucedida do método:

- Utilização de critérios cujas informações estejam disponíveis nas bases de dados da empresa, de forma que a coleta de dados não represente uma sobrecarga ao processo de priorização;

- Possibilidade de inserção de novos critérios ao modelo, de acordo com o interesse do coordenador do CTO e necessidade da área de P\&D, respeitando, porém, o item citado acima;

- Necessidade de melhoria da qualidade da informação inserida nas bases de dados, sendo essa uma atividade que envolve a participação do próprio coordenador do $\mathrm{CTO}$ e das equipes executoras dos projetos de P\&D;

- Possibilidade de revisão dos pesos dos critérios pelos coordenadores de CTO em tempo real, sem que seja necessária a participação do analista de decisão nessa atividade.

Relativamente ao item "Possibilidade de inserção de novos critérios ao modelo", cabe esclarecer que alguns dos critérios sugeridos pelos coordenadores de CTO foram inseridos no modelo e outros não. Os critérios inseridos foram Avaliação e Alinhamento Estratégico que, embora de alguma forma aparecessem na proposta inicial, tiveram seu significado modificado, constituindo-se em novos critérios. Os critérios não inseridos e os motivos da não-inserção estão listados a seguir:

- Taxa de Acidentados Registráveis (TAR): o TAR se aplica a apenas a uma parte dos projetos do portfólio de $\mathrm{P} \& \mathrm{D}$, o que causaria um desequilíbrio na pontuação e ranqueamento final dos projetos.

- Análise Preliminar de Risco (APR): o modelo proposto utilizou o método de análise de riscos vigente na área de $\mathrm{P} \& \mathrm{D}$ da empresa, o qual avalia o risco em função do nível de maturidade tecnológica do projeto. Por sua vez, o APR constitui uma proposta local de análise de riscos, não difundida nas demais áreas de P\&D. 
- Transformação digital: não há definição formal na empresa sobre como a transformação digital deve estar representada nos projetos. Uma vez definida e inserida nas bases de dados, não há impedimentos para se adicionar o critério ao modelo.

- Benefício estimado pela a ordem de grandeza do retorno financeiro esperado para o projeto: informação inexistente nas bases de dados da empresa. Assim como no caso da transformação digital, o benefício poderá ser inserido no modelo sob a condição de haver a informação disponível na base de dados.

- Alinhamento Estratégico em função da importância do desafio tecnológico: a empresa em estudo não estabelece graus de importância para os desafios tecnológicos, sendo todos considerados de igual relevância.

Em linha com o relato dos responsáveis pelas carteiras de $\mathrm{P} \& \mathrm{D}$, espera-se que a implementação do apoio multicritério à decisão venha a conduzir os decisores à escolha dos projetos de $\mathrm{P} \& \mathrm{D}$ com o maior potencial de retorno, sem que o processo de construção das recomendações com base no método multicritério sobrecarregue a realização das reuniões de CTO.

Como benefícios percebidos para a empresa, podemos destacar:

- Seleção dos projetos de maior potencial de retorno para a empresa;

- Conferir racionalidade ao processo decisório, percebido pela equipe de projetos, que faz as propostas de projeto de $\mathrm{P} \& \mathrm{D}$ e conhece os critérios que irão levar suas propostas a serem ou não selecionadas, e pela área cliente, que participa da decisão sobre os projetos e passa a ter uma ferramenta objetiva para auxiliar a priorização dos projetos;

- Melhoria da qualidade da informação inserida, haja vista que o processo decisório proposto levará em consideração as informações existentes nas bases de dados. Logo, as equipes de projeto, que são as responsáveis pelo fornecimento dos dados, sentirão os impactos das informações preenchidas e não-preenchidas.

Com base nos resultados do estudo de caso realizado, acredita-se que o apoio multicritério a decisão possa ser aplicado em portfólios de projetos com características semelhantes ao estudado, ou seja, com grande quantidade de projetos, múltiplos fóruns de decisão e periódicas tomadas de decisão, devendo ser observadas as particularidades do caso específico.

De forma mais ampla, esta pesquisa serviu para demonstrar que, mesmo em cenários com uma quantidade elevada de alternativas e tomadas de decisão frequentes, é viável se empregar a análise multicritério como ferramenta de suporte à decisão.

\subsection{Limitações da pesquisa e recomendações para estudos futuros}

Este trabalho realiza o ranqueamento de projetos de P\&D sem considerar suas possíveis interdependências. Sendo assim, o método proposto pode orientar a escolha de um projeto $\mathrm{A}$ e a não-escolha de um projeto $\mathrm{B}$, sem considerar que esses projetos possuem uma suposta dependência entre si que os impediria de serem selecionados um sem o outro. Acerca deste problema, recomenda-se a leitura de Behrens (2015) e Bhattacharyya (2015). 
Este trabalho tampouco se propõe a realizar a escolha do melhor portfólio dentre todos os possíveis. O método proposto analisa os projetos isoladamente e os ordena conforme a avaliação dos seus critérios. Possivelmente, haverá combinações de projetos que irão resultar em portfólios mais interessantes do que o proposto pelo método. Para este assunto, recomendamos Salo, Keisler e Morton (2011).

A qualidade e disponibilidade da informação são questões críticas no processo de decisão. Leslio e Salo (2008) consideram que é possível prover recomendações de decisão baseando-se em informações incompletas. Tendo-se em conta o grande esforço despendido na atividade de coleta e adequação das informações, recomendamos o aprofundamento deste assunto.

No que tange aos critérios utilizados e à futura implementação do método multicritério na empresa, recomenda-se o aprofundamento da análise do critério "Risco". Entende-se que o método para o cálculo de riscos sugerido por LeGresley et al. (2000) seja demasiadamente simplificado, embora de uma praticidade que justifica a sua utilização.

\section{REFERÊNCIAS BIBLIOGRÁFICAS}

Arratia M, N. M., F. López I, S. E. Schaeffer, e L. Cruz-Reyes. "Static R\&D project portfolio selection in public organizations." Decision Support Systems, 2016: 53-63. doi: 10.1016/j.dss.2016.01.006

Autor. "Google Drive." Fontes de dados e ranqueamento dos projetos. 01 de nov. de 2018. https://docs.google.com/spreadsheets/d/10nHhblubRxvYjW44zqMbjAgoYUuHJZSqIUNy5ENFGWY

Behrens, J. "A Lack of Insight: An Experimental Analysis of R\&D Managers' Decision Making in Innovation Portfolio Management." Creativity and Innovation Management 25, no 2 (dez. 2015): 239-250. doi: 10.1111/caim.12157

Bhattacharyya, Rupak. "A Grey Theory Based Multiple Attribute Approach for R\&D Project Portfolio Selection." Fuzzy Information and Engineering 7, $\mathrm{n}^{\mathrm{o}} 2$ (jun. 2015): 211-225. doi: 10.1016/j.fiae.2015.05.006

Çağlar, Musa, e Sinan Gürel. "Impact assessment based sectoral balancing in public R\&D project portfolio." Socio-Economic Planning Sciences, 25 de Julho de 2018. doi: 10.1016/j.seps.2018.07.001

Clemen, Robert T, e Terence Reilly. Making Hard Decisions with Decision Tools. 3. Edição: Cengage Learning. Mason, OH, USA: South-Western, 2013. [GS Search]

Cooper, R G, S J Edgett, e E J Kleinschmidt. "Portfolio management for new product development: results of an industry practices study." $R \& D$ Management $31, \mathrm{n}^{\circ} 4$ (jan. 2001): 361-380. [GS Search]

Gareis, R. "Management by projects: the management approach for the future." International Journal of Project Management 7, $\mathrm{n}^{\mathrm{o}} 4$ (11 1989): 243-249. doi: 10.1016/0263-7863(89)90013-6

Gomes, L. F. A. M. Teoria da Decisão. São Paulo: Thomson Learning, 2007. [GS Search] 
Gomes, L. F. A. M, e C. F. S Gomes. Tomada de decisão gerencial: enfoque multicritério. 5a. São Paulo: Atlas, 2014. [GS Search]

Gomes, L. F. A. M, M. C. G Araya, e C Carignano. Tomada de Decisões em Cenários Complexos. São Paulo: Pioneira Thomson Learning, 2004. [GS Search]

Gonzaga, S, e A C Menezes. "Metodologia para Priorização de Projetos no Cenpes.” Rio de Janeiro, 1997.

Hammond, John S, Ralph L Keeney, e Howard Raiffa. "The Hidden Traps in Decision Making." Harvard Business Review, Set-Out 1998. https://hbr.org/2006/01/thehidden-traps-in-decision-making

Keeney, R L, e H Raiffa. Decisions with Multiple Objectives: Preferences and Value Tradeoffs. Cambridge: Cambridge University Press, 1993. [GS Search]

Kloc, D, e F Sidi. "Data: Foundation of Digital Transformation.” DellEMC Forum, Madrid, 2017. https://www.dellemc.com/content/dam/uwaem/production-designassets/es-es/events/forums/digital/2017/post-event/presentations/digital-5.pdf

LeGresley, P, et al. "1998/1999 AIAA Foundation Graduate Team Aircraft Design Competition: Super STOL Carrier On-board Delivery Aircraft." American Institute of Aeronautics and Astronautics - Stanford University, Stanford, 2000. doi: $10.2514 / 6.2000-5535$

Leite, L F. "Metodologia de Seleção, Avaliação e Priorização de Projetos Tecnológicos Inovadores." Tese (Doutorado em Tecnologia de Processos Químicos e Bioquímicos) - Escola de Química / UFRJ, 2008, 210. http://186.202.79.107/download/priorizacaode-projetos-tecnologicos-inovadores.pdf

Leslio, J, e A Salo. "Scenario-based portfolio selection of investment projects with incomplete probability and utility information." Helsinki University Technology, Systems Analysis Laboratory Research Report, Helsinki, 2008. https://www.sciencedirect.com/science/article/pii/S0377221711007661

Magalhães, R F, L. A. D. Rangel, e C A Silva. "Utilização do Apoio Multicritério à Decisão para Avaliação de Órgãos de Fomento Pesquisa." Simpósio de Excelência em Gestão e Tecnologia. Rio de Janeiro, 2017. https://www.aedb.br/seget/arquivos/artigos17/22625340.pdf

Mankins, J C. “Technology Readiness Levels - A White Paper.” Office of Space Access and Technology, NASA., Washington, EUA, 1995. [GS Search]

Miranda, Z. "Sistema de inovação no setor aeronáutico: desafios e oportunidades para o Brasil.” Instituto de Pesquisa Econômica Aplicada (IPEA), Brasília, 2016. [GS Search]

Mohagheghi, V., S. M. Mousavi, B. Vahdani, e M. R. Shahriari. "R\&D project evaluation and project portfolio selection by a new interval type-2 fuzzy optimization approach." Neural Computing and Applications, Dezembro de 2017: 3869-3888. doi: 10.1007/s00521-016-2262-3

Organização de Cooperação e Desenvolvimento Econômico. Manual de Frascati: Metodologia proposta para definição da pesquisa e desenvolvimento experimental. 
Rio de Janeiro: F-Iniciativas, 2013. www.ipdeletron.org.br/wwwroot/pdfpublicacoes/14/Manual_de_Frascati.pdf

Osmundsen, Karen, Jon Iden, e Bendik Bygstad. "Digital Transformation: Drivers, Success Factors and Implications." Mediterranean Conference on Information Systems (MCIS), 2018: 37. https://aisel.aisnet.org/mcis2018/37

Project Management Institute. The Standard for Portfolio Management. Fourth. Pennsylvania, EUA: Project Management Institute, Inc, 2017. [GS Search]

-. Um Guia do Conhecimento em Gerenciamento de Projetos (Guia PMBOK). $6^{\mathrm{a}}$. Pennsylvania, EUA: Project Management Institute, Inc, 2018. [GS Search]

Rodriguez, M. V. R. "O Estabelecimento de Regras para a Priorização de Projetos de Tecnologia." Tese (Doutorado em Engenharia Civil) - COPPE/UFRJ, Rio de Janeiro, 2000, 299. http://www.coc.ufrj.br/pt/teses-de-doutorado/144-2000/901-martiusvicente-rodriguez-y-rodriguez

Roussel, P, K Saad, e N Bohlin. Pesquisa \& desenvolvimento: Como integrar P\&D ao plano estratégico e operacional das empresas como fator de produtividade $e$ competitividade. Edição: Tradução José Carlos Barbosa dos Santos e revisão técnica Moysés Gedanke. São Paulo: Makron Books, 1992. [GS Search]

Saaty, T. L. The Analytic Hierarchy Process. New York: McGraw-Hill, 1980. [GS Search]

Salo, A, J Keisler, e A Morton. An Invitation to Portfolio Decision Analysis. Vol. 162, cáp. 1 em Portfolio Decision Analysis, por edição: A Salo, J Keisler e A Morton, 409. New York: Springer, 2011. doi: 10.1007/978-1-4419-9943-6_1

Saramago, L. F. M. "Priorização de Proposições de Projetos de Pesquisa e Desenvolvimento na Petrobras: Uma análise comparativa entre os métodos Direct Rating e Swing Weighting." Dissertação (Mestrado em Administração) - Faculdade de Administração e Economia, Ibmec, Rio de Janeiro, 2010, 68. http://s3.amazonaws.com/public-cdn.ibmec.br/portalibmeccontent/public/arquivos/df/dis_2010_27___luiz_felipe_mathias_saramago.pdf

Tervonen, Tommi, Juuso Liesio, e Ahti Salo. "Modeling project preferences in multiattribute portfolio decision analysis." European Journal of Operational Research 263, no 1 (nov. 2017): 225-239. doi: 10.1016/j.ejor.2017.04.051

Vecchio, P D, A D Minin, A M Petruzzelli, U Panniello, e S Pirri. "Big data for open innovation in SMEs and large corporations: Trends, opportunities, and challenges." Creativity and Innovation Management 27, $\mathrm{n}^{\circ} 1$ (jul. 2017): 6-22. [GS Search]

Yamaguishi, S H. "Gestão da inovação na indústria farmacêutica no Brasil: estudo de múltiplos casos." Tese (Doutorado em Tecnologia Nuclear) - Instituto de Pesquisas Energéticas e Nucleares, USP, São Paulo, 2014, 225. [GS Search]

Zeleny, M. "Strategy as Action: from Porter do Anti-Porter." Int. J. Strategic Decision Sciences 1, no 1 (2010): 1-22. [GS Search]

Zink, Olivia Silva. "Avaliação e seleção de projetos de P\&D na Petrobras: Desenvolvimento de um modelo para o segmento de Abastecimento através da 
metodologia AHP." Monografia (Especialização em Business Inteligence) Departamento de Engenharia Elétrica da PUC/Rio, Rio de Janeiro, 2009, 70. 